\title{
Alterações visuais decorrentes do cisto da fenda de Rathke - Relato de caso
}

\author{
Visual alterations due to Rathke's cleft cyst-Case report
}

\author{
Gustavo Valandro Rech ${ }^{1}$ \\ John Prochnau ${ }^{2}$ \\ Rosangela Rosa da Rosa ${ }^{3}$ \\ Othello Moreira Fabião Neto ${ }^{4}$ \\ Fernando Antônio de Oliveira Costa ${ }^{5}$
}

Trabalho realizado pelo Departamento de Oftalmologia e pelo Departamento de Neurocirurgia do Hospital Universitário São Francisco de Paula (HUSFP) da Universidade Católica de Pelotas - UCPEL.

${ }^{1}$ Residente do primeiro ano do Hospital Banco de Olhos de Porto Alegre.

2 Acadêmico da Faculdade de Medicina da Universidade Católica de Pelotas - UCPEL.

${ }_{3}^{3}$ Professora Adjunta do Departamento de Oftalmologia da Faculdade de Medicina da Universidade Católica de Pelotas - UCPEL.

${ }^{4}$ Professor do Departamento de Neurologia da Faculdade de Medicina da Universidade Federal de Pelotas UFPEL e Universidade Católica de Pelotas - UCPEL. Mestre em Neurocirurgia pela Universidade Federal de São Paulo - UNIFESP.

${ }^{5}$ Professor do Departamento de Neurologia da Faculdade de Medicina da Universidade Católica de Pelotas UCPEL. Doutor em Neurocirurgia pela Universidade Federal de São Paulo - UNIFESP.

Endereço para correspondência: Gustavo Valandro Rech - Rua Eng. Walter Boehl, 270/401 - Porto Alegre (RS) CEP 91360-090

E-mail: gustavovrech@bol.com.br

Recebido para publicação em 24.10.2003

Versão revisada recebida em 28.04.2004 Aprovação em 07.07.2004

Nota Editorial: Pela análise deste trabalho e por sua anuência na divulgação desta nota, agradecemos à Dra. Maria Kyoko Oyamada.

\section{RESUMO}

Os cistos da fenda de Rathke são lesões para-selares, geralmente assintomáticas, presentes em 12 a 33\% das autópsias de pacientes com hipófise normal. Ocasionalmente, os cistos podem aumentar de volume a ponto de comprimir estruturas supra-selares e intra-selares, levando ao aparecimento dos sintomas. Clinicamente, os pacientes referem escurecimento visual, além de apresentarem defeitos campimétricos. M.A.S.R., 47 anos, sexo feminino, branca, natural de Pelotas/RS com queixa de embaçamento progressivo da visão do olho direito há 2 meses. Ao exame, constatou-se baixa visual e hemianopsia bitemporal. A tomografia computadorizada evidenciou imagem hipodensa arredondada, de bordos nítidos, em topografia selar, determinando remodelação e alargamento da sela túrcica. A ressonância magnética mostrou lesão expansiva cística localizada na sela túrcica com crescimento supra-selar. A referida lesão apresenta obliteração da cisterna supra-selar e importante compressão sobre o quiasma óptico. A abordagem cirúrgica confirmou a presença de lesão expansiva cística comprimindo o quiasma óptico e o exame de anatomia patológica do material diagnosticou cisto da fenda de Rathke. O exame oftalmológico, três meses após a cirurgia, mostrou melhora da acuidade visual e recuperação total dos defeitos do campo visual. O cisto da fenda de Rathke deve ser incluído no diagnóstico diferencial dos tumores para-selares passíveis de causar compressão da via óptica nervosa e ressalta-se a importância do diagnóstico e tratamento precoce no intuito de prevenir danos estruturais com perdas irreversíveis da função visual, bem como os distúrbios endócrinos.

Descritores: Hemianopsia; Campo visual; Cistos; Sela túrcica/cirurgia; Doenças hipofisárias; Cultivo de tecido; Imagem por ressonância magnética

\section{INTRODUÇÃ̃O}

Os cistos da fenda de Rathke são lesões para-selares, geralmente assintomáticas, presentes em $12 \%$ a $33 \%$ das autópsias de pacientes com hipófise normal $^{(1-2)}$.

A manifestação de sintomas é rara ${ }^{(2-3)}$. Ocasionalmente, os cistos podem aumentar de volume a ponto de comprimir estruturas supra-selares e intraselares, levando ao aparecimento dos sintomas, devido a distúrbio hipofisário-hipotalâmico-quiasmático ${ }^{(1)}$. Foram relatados, até 1977 , apenas $34 \operatorname{casos}^{(4)}$. Em 1992 esse número aumentou para 87, passando para 150 casos histologicamente confirmados em $1997^{(5)}$. Este aumento na incidência é dado ao surgimento de novos exames de imagem com maior poder de resolução, como a ressonância magnética. 
Clinicamente os pacientes referem escurecimento visual, além de apresentarem defeitos campimétricos, atrofia óptica e papiledema ${ }^{(1,3,6)}$.

A doença ocorre mais em mulheres adultas, com maior freqüência entre a $5^{\underline{a}}$ e a $6^{\underline{a}}$ décadas de vida ${ }^{(7)}$.

Os pacientes apresentam bom prognóstico visual após descompressão quiasmática cirúrgica. O objetivo desse estudo é documentar um caso de cisto da fenda de Rathke, verificando os diagnósticos diferenciais e o risco de recidiva.

\section{RELATO DO CASO}

M.A.S.R., 47 anos, sexo feminino, branca, natural de Pelotas/RS, procurou atendimento oftalmológico referindo embaçamento progressivo da visão do olho direito (OD) há 2 meses e "sensação de pressão" no fundo desse olho. Usa correção óptica desde os 4 anos de idade e referiu antecedentes pessoais de estrabismo, câncer de mama, com cirurgia oncológica há 5 meses, e amenorréia há 4 meses.

Ao exame oftalmológico apresentava acuidade visual, com correção, de 20/80 no OD e 20/20 no OE. O reflexo fotomotor direto OD e consensual do OE apresentou-se diminuído, além de anisocoria discreta com pupila maior à D. A pressão intra-ocular foi de $14 \mathrm{mmHg}$ em ambos os olhos. A fundoscopia mostrou diminuição do pulso venoso e discreto edema do disco óptico no OD, não apresentando alterações no OE. Ao exame de campo visual de confrontação apresentou hemianopsia bitemporal.

O exame neurológico não revelou outras alterações e a tomografia computadorizada (TC) de crânio mostrou uma imagem hipodensa arredondada, de bordos nítidos, densidade intermediária entre líquido e partes moles, medindo cerca de 2,3 x 2,7 cm de diâmetro em topografia supra-selar, determinando remodelação e alargamento da sela túrcica. As estruturas e vasos selares e para-selares mostraram-se comprimidos e rechaçados. A TC apresentou como diagnóstico diferencial craniofaringioma, cisto epitelial e cisto da fenda de Rathke (Figura 1).

A ressonância magnética evidenciou lesão expansiva cística localizada na sela túrcica, com crescimento supra-selar, medindo cerca de 3,4 × 2,8 cm x 2,4 cm em seus maiores diâmetros, sem realce após o uso endovenoso de contraste. Apresentava obliteração da cisterna supra-selar e importante compressão sobre o quiasma óptico, sugestivo de macroadenoma predominantemente cístico (Figuras 2 e 3 ).

A avaliação laboratorial pré-operatória de rotina não mostrou alterações.

Aproximadamente um mês após sua primeira consulta, a paciente foi submetida a uma craniotomia fronto-temporal, com abordagem da lesão e descompressão do quiasma óptico. O exame anátomo-patológico revelou tratar-se de cisto da fenda de Rathke, com conteúdo líquido contendo alguns histiócitos. No pós-operatório evoluiu com meningite, tendo ótima recuperação e melhora progressiva das alterações visuais.

A acuidade visual do OD, cerca de três meses após a cirurgia, era de 20/30 e recuperação total do defeito campimétrico.

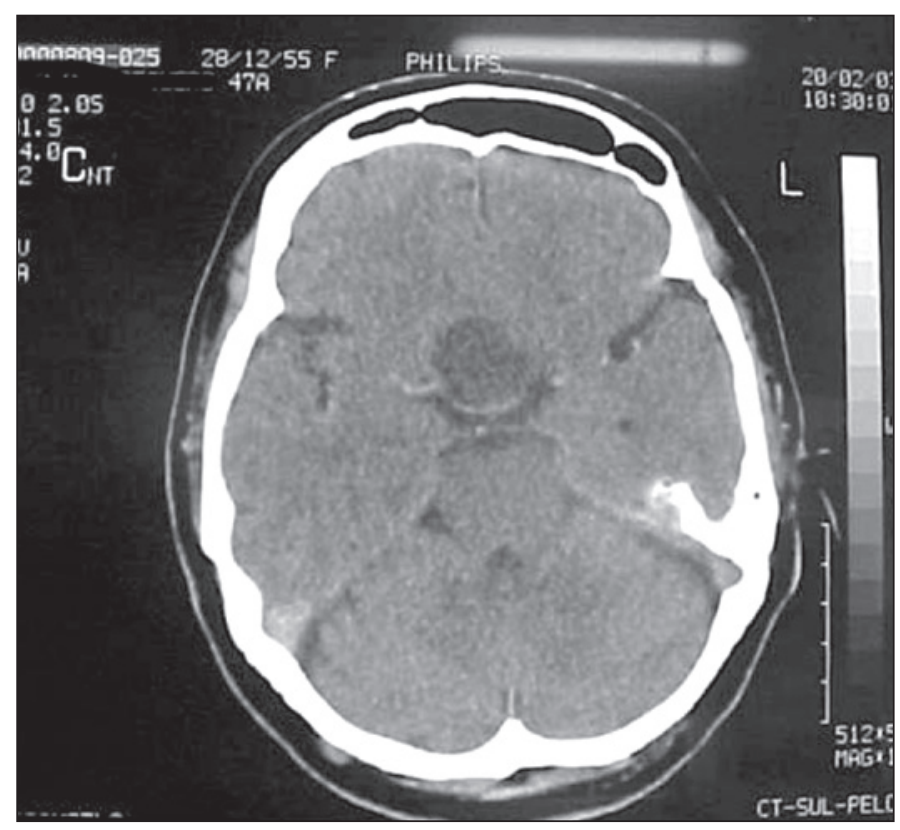

Figura 1 - Tomografia computadorizada de crânio. Corte axial

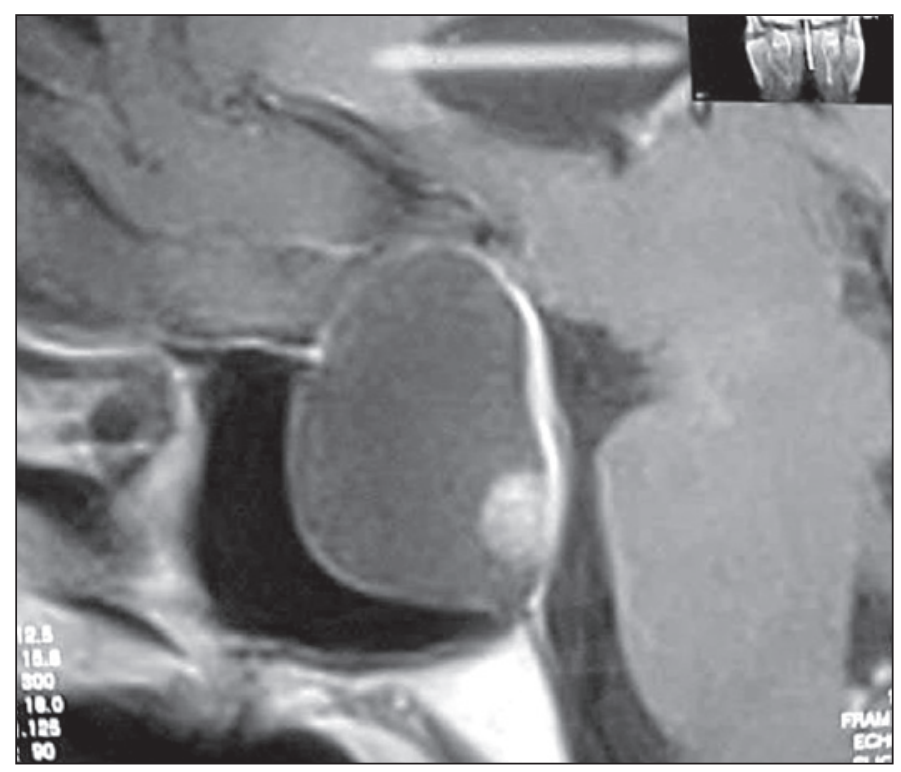

Figura 2 - Ressonância Magnética de crânio. Corte sagital

\section{DISCUSSÃO}

O cisto da fenda de Rathke é originário de remanescentes da fenda de Rathke, formada ao redor da quinta semana de gestação ${ }^{(2-4)}$. A origem, segundo alguns autores, é de tecido neuroepitelial ${ }^{(8)}$, do endoderma ${ }^{(9-10)}$ ou das células da hipófise anterior, por metaplasia reversa ${ }^{(11)}$. A formação desses cistos pode ser resultado da falha na obliteração da fenda de Rathke, com proliferação e acúmulo de secreção no seu interior ${ }^{(1-3,12)}$.

Em necrópsias de rotina e exames de imagem neurológicos da região hipotálamo-hipofisária, esses cistos podem ser en- 


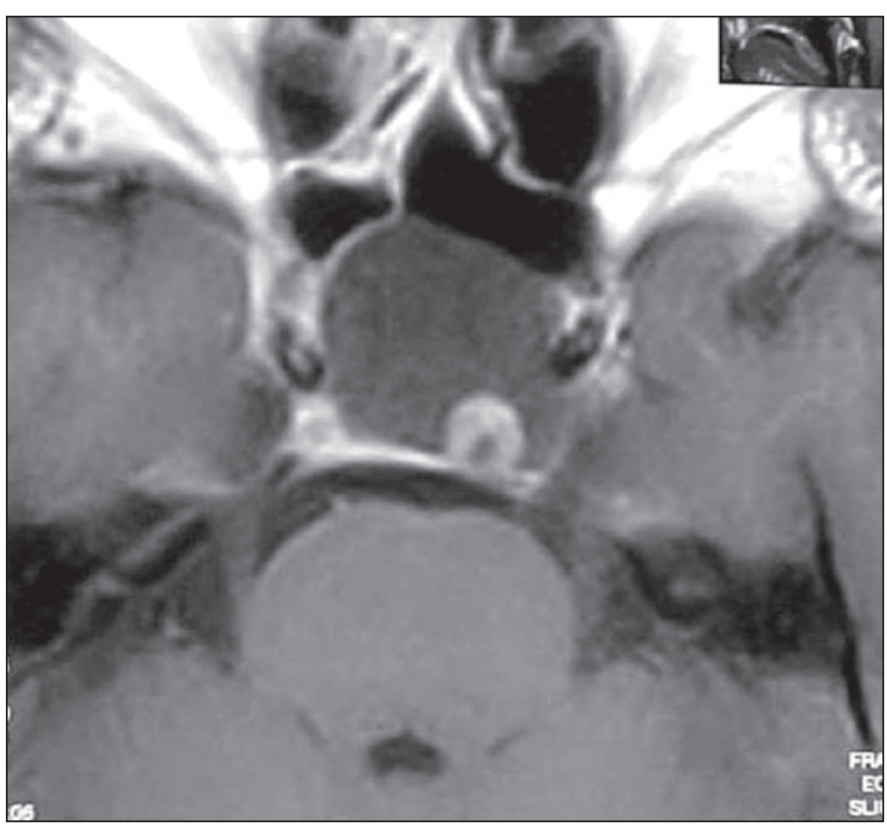

Figura 3 - Ressonância Magnética de crânio. Corte axial

contrados em $12 \%$ a $33 \%$ das pessoas com hipófise normal ${ }^{(1-2)}$. Geralmente são assintomáticos ${ }^{(2-3)}$. O primeiro caso com aumento do volume do cisto a ponto de comprimir estruturas supra-selares e intra-selares, levando ao aparecimento dos sintomas, foi descrito por Goldzeiher em 1913(4). Até 1997, foram observados aproximadamente 150 casos histologicamente confirmados ${ }^{(1-3,5,13)}$. A doença predomina no sexo feminino, na proporção de $2: 1$, e entre a $5^{\underline{a}}$ e $6^{\underline{a}}$ décadas de vida ${ }^{(7)}$. Os sinais e sintomas iniciais geralmente surgem de um distúrbio hipofisário-hipotalâmico-quiasmático combinado ${ }^{(1,13)}$.

Os achados mais freqüentes, em crianças, são a diminuição da acuidade visual e diabetes insípidus, seguidos por adiposidade, cefaléia e vômitos. Em adultos, observa-se amenorréia, paresia espástica discreta em membros inferiores, cefaléia, deficiência visual quiasmática e confusão mental ${ }^{(1-2,13)}$.

Alguns autores ${ }^{(14)}$ concluíram de 28 casos estudados de cistos da fenda de Rathke, 50\% apresentaram distúrbios endócrinos, $32,1 \%$ cefaléia e $14,3 \%$ distúrbios visuais.

Autores ${ }^{(5)}$, estudando 12 pacientes com cisto da fenda de Rathke, constataram cefaléia em $91 \%$ dos pacientes, hiperprolactinemia em $18 \%$ e amenorréia em $63 \%$.

O número de casos relatados de cisto da fenda de Rathke aumentou consideravelmente após $1977^{(1)}$. Isso se deve à modernos exames de imagem com maior poder de resolução como a TC e a $\mathrm{RM}^{(1-3,13)}$.

O diagnóstico diferencial mais importante é feito com os craniofaringiomas, contudo outros tumores desta região devem ser considerados, como os gliomas hipotalâmicos e meningiomas, mesmo que estes tumores tenham diferenças significativas no seu contorno e localização. Algumas características são úteis para distinguir a imagem dos cistos da fenda de Rathke dos craniofaringiomas, como o tamanho do cisto, a idade do paciente, já que a maior incidência dos craniofaringiomas ocorre em pacientes com idade abaixo de 20 anos e os cistos da fenda de Rathke são mais freqüentes em adultos, e a presença ou não de captação na parede do cisto(13). As imagens radiológicas características de cisto da fenda de Rathke são de uma lesão com epicentro selar, de contornos lisos, ausência de calcificações e de realces internos e apresentação homogênea à $\mathrm{RM}^{(14)}$. Alguns autores relataram que foram incapazes de identificar qualquer achado característico nas imagens de TC ou de RM que pudessem diferenciar os cistos da fenda de Rathke de outras lesões, como o faringioma e os cistos adenomas hipofisários ${ }^{(2,8,15)}$.

Os achados diagnósticos dos exames de imagem indicam os casos que necessitam de tratamento cirúrgico devido a alterações compressivas ou endocrinológicas e sugerem prováveis diagnósticos, porém para o diagnóstico definitivo, deve ser histologicamente confirmado.

O tratamento cirúrgico dos cistos da fenda de Rathke tem as mesmas indicações que as dos adenomas não-funcionantes, ou seja, compressão de estruturas nervosas da região quiasmática e para quiasmática, ou de manifestações endócrinas devido a distúrbio do eixo hipotálamo-hipofisário ${ }^{(13)}$.

A recidiva dos cistos da fenda de Rathke é rara ${ }^{(5)}$. Somente alguns autores, mostraram casos de recidiva bem documenta$\operatorname{dos}^{(16-17)}$. Segundo alguns autores ${ }^{(5)}$, o risco de recorrência aumenta nos casos com parte sólida, que contenha epitélio escamoso estratificado, dentro do cisto. O exame de anatomia patológica do cisto dessa paciente mostrou conteúdo apenas líquido, revelando um bom prognóstico quanto ao risco de recidiva.

No presente caso, encontramos muitos dos achados da literatura, como sexo feminino, faixa etária, diminuição da acuidade visual, hemianopsia bitemporal, além de distúrbio hormonal relacionado ao hipogonadismo, a amenorréia. A indicação do tratamento cirúrgico nessa paciente foi devido a compressão do quiasma óptico e um possível distúrbio endócrino, confirmado com a reversão do hipogonadismo após a cirurgia. Ressalta-se a importância do diagnóstico e conduta precoce, no sentido de evitar um maior comprometimento visual, além do aparecimento de outros sinais e sintomas dos distúrbios hormonais.

Portanto, frente a pacientes com tais manifestações visuais, deve-se incluir o cisto da fenda de Rathke no diagnóstico diferencial dos tumores da região selar.

\section{ABSTRACT}

Rathke's cleft cysts are parasellar lesions, which are usually asymptomatic and found in 12 to $33 \%$ of autopsies done on patients with normal pituitary gland. Occasionally, the cysts can swell up to the point of putting pressure on the suprasellar and intrasellar structures, which provoke the symptoms. Clinically, the patients complain about blurred vision and they also present hemianopsia deficiency. M.A.S.R., 47 years old, female, white, born in Pelotas/RS, complained about progressive vision reduc- 
tion in the right eye for 2 months. During the examination, loss of vision and bitemporal hemianopsia were discovered. Computerized tomography highlighted a rounded hypodense image with clear borders, in sellar topography, determining remodeling and enlarging of the sella turcica. Magnetic resonance showed expansive cystic injury located in the sella turcica with suprasellar growth. The mentioned injury presented obliteration in the suprasellar cistern and an important compression on the optic chiasm. The surgical approach confirmed the presence of extensive cystic injury compressing the optic chiasm, and the anatomicopathological examination of the material diagnosed Rathke's cleft cyst. The ophthalmic examination three months after the surgery showed improvement in visual accuracy and total recovery of defects of the visual field. Rathke's cleft cyst must be included in the differential diagnosis of parasellar tumors which may cause compression of optical pathway, and the importance of the diagnosis and immediate treatment with the purpose of avoiding structural damages with unreversible losses of visual function, as well as endocrine disorders are emphasized.

Keywords: Hemianopsia; Visual field; Cysts; Sella turcica/ surgery; Pituitary diseases; Tissue cultures; Magnetic resonance imaging

\section{REFERÊNCIAS}

1. Voelker JR, Campbell RL, Muller J. Clinical, radiographic, and pathological features of symptomatic Rathke's cleft cysts. J Neurosurg. 1991;74(4):535-44.
2. Oka H, Kawano N, Suwa T, Yada K, Kan S, Kameya T. Radiological study of symptomatic Rathke's cleft cysts. Neurosurgery. 1997;35(4):632-6; discussion p.636-7.

3. Ross D, Norman D, Wilson C. Radiologic characteristics and results of surgical management of Rathke's cysts in 43 patients. Neurosurgery. 1992;30(2):173-80.

4. Yoshida J, Kobayashi T, Kageyama N, Kanzaki M. Symptomatic Rathke's cleft cyst. Morphological study with light and electron microscopy and tissue culture. J Neurosurg. 1977;47(3):451-8.

5. Mukherjee JJ, Islam N, Kaltsas G, Lowe DG, Charlesworth M, Afshar F, et al. Clinical, radiological and pathological features of patients with Rathke's cleft cysts: tumor that may recur. J Clin Endocrinol Metab. 1997;82(7):2357-62.

6. Fischer EG, DeGirolami U, Soujanen JN. Reversible visual deficit following debulking of a Rathke's cleft cyst: a tethered chiasm. J Neurosurg. 1994;81(3): 459-62.

7. Agnetti V, Carreras M, Rocca A, Turtas S, Viale GL. Epithelial cysts related to the Rathke's cleft. J Neurosurg Sci. 1974;18(1):65-9.

8. Diengdoh JV, Scott T. Electron-microscopical study of a Rathke's cleft cyst. Acta Neuropathol (Berl). 1983;60(1-2):14-8.

9. Matsushima T, Fukui M, Fujii K, Kinoshita K, Yamakawa Y. Epithelial cells in symptomatic Rathke's cleft cysts. A light and electron-microscopic study. Surg Neurol. 1988;30(3):197-203.

10. Graziani N, Dufour H, Figarella-Branger D, Donnet A, Bouillot P, Grisoli F. Do the suprasellar neuroenteric cyst, the Rathke's cleft cyst and the colloid cyst constitute a same entity. Acta Neurochir (Wien). 1995;133(3-4):174-80.

11. Naiken VS, Tellem M, Meranze DR. Pituitary cyst of Rathke's cleft origin with hypopituitarism. J Neurosurg. 1961;18:703-8.

12. Steinberg Gk, Koening Gh, Golden JB. Symptomatic Rathke's cleft cysts: report of two cases. J Neurosurg. 1982;56(2):290-6.

13. Rodrigues FF, Cappabianca P, Violante AH. Cistos na bolsa de Rathke: diagnóstico e tratamento. Arq Neuropsiquiatr. 2001;59(1):101-5.

14. El-Mahdy W, Powell M. Transsphenoidal management of 28 symptomatic Rathke's cleft cysts with special reference to visual and hormonal recovery. Neurosurgery. 1998;42(1):7-16; discussion p.16-7.

15. Sumida M, Uozimi T, Mukada K, Arita K, Kurisu K, Eguchi K. Rathke cleft cysts: correlation of enhanced MR and surgical fidings. AJNR Am J Neuroradiol. 1994;15(3):525-32.

16. Berry RG, Schlezinger NS. Rathke's cleft cysts. Arch Neurol 1959;1:48-58.

17. Fairburn B, Larkin IM. Cysts of Rathke's cleft. J Neurosurg. 1966;24(1):77-81. 